\title{
Pattern of Vascular Diseases at Tikur Anbessa Specialized Hospital, Addis Ababa, Ethiopia
}

\author{
Nebyou Seyoum ${ }^{1}$, Dawit G/giorgis ${ }^{1}$, Berhanu Nega ${ }^{1}$
}

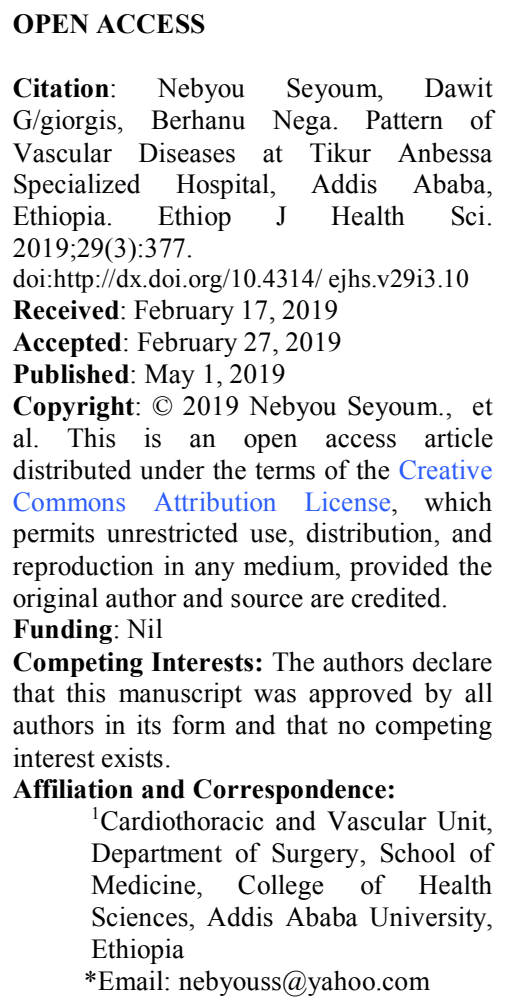

\section{ABSTRACT}

BACKGROUND: Vascular diseases are evolving fast in subSaharan Africa, but its management is challenged by lack of expertise and infrastructure. In the light of the prevailing challenge, this study was done to see the pattern of vascular disease and its treatment in a tertiary referral hospital.

METHODS: A prospective cross-sectional study was done over a period of one year (February 9, 2016 to February 8, 2017) at Tikur Anbessa specialized hospital (TASH) at Addis Ababa, Ethiopia.

RESULTS: A total of 386 patients were seen at the surgical OPD. Of these, $78(20.2 \%)$ were admitted and operate on. The male to female ratio was 1.3:1. The mean age affected was $39+/-10$ (Range 12-91 years). On the other hand, 132 (34.2\%) patients came with $P A D$. Of them, 46(34.8\%) presented with either frank Gangrene or pre-gangrene stage. The rest 86(65.1\%) had claudication pain. The other diseases seen are Varicose Vein, 100(25.9\%), Carotid body tumors, 60(15.4\%), Aneurysmal diseases, 36(9.1\%), Vascular malformations, 34(8.7\%), and Vascular injuries, 22(5.6\%). During the study period, 28(35.9\%) PAD, 22(28.2\%) trauma patients, 8(10.2\%) Chemodectomas, 8(10.2\%) aneurysms, 6(7.7\%) hemangiomas, $4(5.1 \%)$ varicose vein and 2(2.6\%) AV fistula patients were operated.

CONCLUSION: The pattern of vascular disease in Ethiopia is becoming a challenge. The gap created due to limited vascular surgeons, poor infrastructure and absent supply chain system has significantly compromised the number and type of operated-on patients. These challenges result in preventable morbidity and mortality.

KEYWORDS: Pattern of vascular diseases, vascular trauma, peripheral arterial disease

\section{INTRODUCTION}

The burden of non-communicable diseases (NCD) is increasing, accounting for nearly half of the total global burden of disease. Almost $50 \%$ of the adult disease burden in low- and middle-income countries is now attributable to non-communicable diseases (1). Non-communicable diseases are the number one world's killer, causing $60 \%$ of all deaths globally and a staggering 35 million people die every year from these silent killers (2). In 2008, this 
figure rose to 36.1 million (i.e. about $63 \%$ of global deaths), and $80 \%$ of the NCD deathsequivalent of 29 million people occurred in low and middle-income countries with the projection of about 52 million deaths annually by 2030 (2).

Low and middle-income countries (LMICs) had a significant increase in the burden from these conditions. The trend mirrors that of the risk factors for vascular disease, namely advanced age, tobacco use, diabetes mellitus and hypertension. In most LMICs, perhaps of equal importance is the lack of public health infrastructure and primary care systems to promote primary and secondary prevention of these non-communicable disease epidemics (3).

In Ethiopia today,there are evidences that show traumatic vascular injuries, atherosclerotic arterial lesions, different venous and lymphatic diseases, aneurysmal diseases as well as carotid body tumors are very common. In Tikur Anbessa Specialized Hospital, during the year 2010/2011, $12 \%$ of cardiothoracic and vascular surgery unit admissions were vasculardiseases (5). According to Berhe etal (6), the most common indications for amputation were trauma $(37.7 \%)$, tumor $(24.1 \%)$, and peripheral arterial disease (PAD) (20.7\%). Similarly, Manyazewal (7) identified that vascular disease, next to trauma, was the second common cause $(32 \%)$ of amputation. Haileab et al (8) also investigated the incidence and predictors of vascular complications among type $2 \mathrm{DM}$ patients at the University of Gondar Referral Hospital, Ethiopia. They found out that cumulative incidence of vascular complications during the study period after a median follow-up time of 6.8 years were $28 \%$, and the incidence rate of vascular complications was 40.6 cases per 1000 person-year observation.

The objective of this study is to assess the magnitude, pattern and risk factors of vascular diseases in Tikur Anbessa Teaching Hospital. This study will also serve as a baseline for further studies, which will eventually strengthen vascular training and service in the country.

\section{MATERIALS AND METHODS}

This is a one-year (February 9, 2016 to February 8 , 2017) prospective cross-sectional hospital based non-randomized study conducted on all surgical patients who presented to the Vascular Surgery Clinic and Emergency OPD at Tikur Anbessa Specialized Hospital (TASH). The hospital is a central tertiary referral hospital found in Addis Ababa, Ethiopia. One consultant vascular surgeon, six consultant cardiothoracic and two vascular fellow residents provide the service. Twelve visiting professors from the University of Wisconsin (USA) and Linköping (Sweden) also supported the program. The unit runs three outpatient clinics, two operating days for elective vascular surgery and a 24 hours' service for emergency vascular conditions.

During the study period, a total of 386 patients were seen. Of these, 78 patients were admitted to the General Surgical Ward for different interventions. The patients' case notes, bio-data, final diagnosis (as made by the managing specialist), patients investigation done, and the final outcome of the treatment given were entered into a pre-coded spreadsheet. Data was then analyzed with the aid of the Statistical Package for Social Sciences (SPSS Inc, Chicago, IL Version 23). Data were expressed as frequency and percentages. Ethical clearance for the study was obtained from the Ethical Committee of the Department of Surgery at TASH.

\section{RESULTS}

Out of the 386 cases identified for the study, $216(55.9 \%)$ were males and $170(44.1 \%)$ were females $(\mathrm{F}: \mathrm{M}=1: 1.27)$. The mean age of presentation was $39+/-10$ (Range 12-91 years). The majority of the patients, 274(71\%), were from urban areas, primarily from Addis Ababa while $112(29 \%)$ patients came from different rural regions of Ethiopia.

Two hundred and forty (64.9\%) patients with chronic problems had symptoms for more than 6 months and among those with trauma victims, $14 / 22(63.6 \%)$, arrived to the hospital in less than 12 hours. The commonest symptoms seen were

DOI: http://dx.doi.org/10.4314/ejhs.v29i2.10 
leg pain, 140(36\%), Leg swelling 72 (18.6\%), and bleeding from stab injury, 22(5.5\%). Among those who presented with leg pain, the left leg is affected in 56(14.4\%), the right leg in 44(11.3\%) and both legs in $40(10.3 \%)$ patients. Right and left leg swelling was seen in 26(6.7\%) and $30(7.8 \%)$ patients, respectively. Both legs were found swollen in $16(4.1 \%)$ patients.

In the majority of patients with PAD, 244(63.2\%), risk factors for vascular disease were not identified. However, among those with some risk factors, the commonest identified risk factors were smoking, 86(22.3\%), Hypertension, 42(10.9\%), Diabetes Mellitus, 26(6.7\%), and both Hypertension and Diabetes Mellitus, was found in 20(5.2\%). Others risk factors (like Dyslipidemia, HIV infection, Chronic kidney disease \& Cardiac illness) were identified in 54(14\%) patients.

Out of 386 patients seen at surgical OPD, only $78(20 \%)$ patients were operated. Thrombectomy/embolectomy/graft interposition or reverse saphenous vein graft were done for PAD in $28(35.9 \%)$ patients. Repair/reverse saphenous vein graft or Ligation for traumatic vascular injury was done in $22(28.2 \%)$ patients. Excision of Chemodectomas was done in
$8(10.2 \%)$ patients. Graft interposition / excision of pseudo aneurysm or patch angioplasty was done for either abdominal aortic aneurysm or Femoral aneurysm in $8(10.2 \%)$ patients. Excision of hemangiomas was done in $6(7.7 \%)$ patients. Long/short saphenous vein stripping and AV fistula for dialysis were done for $4(5.1 \%)$ and $2(2.5 \%)$ patients respectively.

(Table 1).

The mean hospital stay for the operated cases was 14.8+/-11.31 days, (Range 2-55 days). Eighteen patients $(23 \%)$ had developed one or more complications, and one patient (1.28\%) died. The commonest complication encounters were wound infection, re-thrombosis \& reperfusion injury. The patient who died is a known CRVHD with atrial fibrillation, hypertension and NYHA class IV heart failure admitted to ICU with bilateral dry gangrene of both legs. After stabilizing the heart failure, to minimize the level of amputation, below knee interposition reverse venous graft was attempted which later failed and above knee amputation was done. Subsequently, the patient developed sepsis of wound focus and died of MODS.

Table 1: Vascular surgery done in TASH from February 9, 2016, to February 8, 2017

\begin{tabular}{|c|c|c|c|}
\hline Indication & No. $(\%)$ & Procedure done & Complication (No.) \\
\hline PAD & $28(35.9)$ & $\begin{array}{l}\text {-Thrombectomy/embolectomy/ } \\
\text { Graft Interposition/ reverse saphenous } \\
\text { vein graft/ amputation }\end{array}$ & $\begin{array}{l}\text { - Wound infection (4) } \\
\text { - Re-thrombosis (2) } \\
\text { - Reperfusion Compartment } \\
\text { Syndrome (2) } \\
\text { - Graft failure (1) } \\
\text { - Phantom pain (1) } \\
\text { - Death (1) }\end{array}$ \\
\hline Varicose vein & $4(5.1)$ & $\begin{array}{l}\text { - Multiple ligation/Long or short } \\
\text { saphenous vein stripping }\end{array}$ & - None \\
\hline Chemodectomas & $8(10.2)$ & - Excision & $\begin{array}{l}\text { - Hypoglossal Nerve } \\
\text { Injury (1) }\end{array}$ \\
\hline Aneurysmal diseases & $8(10.2)$ & $\begin{array}{l}\text { - Graft interposition/ Excision of } \\
\text { pseudo aneurysm / Patch angioplasty }\end{array}$ & - Wound infection (1) \\
\hline $\begin{array}{l}\text { Vascular } \\
\text { malformations }\end{array}$ & $6(7.7)$ & - Excision & - None \\
\hline Vascular injury & $22(28.2)$ & $\begin{array}{l}\text { - Repair/ Reverse saphenous vein graft / } \\
\text { Ligation }\end{array}$ & $\begin{array}{l}\text { - Thrombosis (2) } \\
\text { - Reperfusion Injury (1) } \\
\text { - Graft Failure (1) } \\
\text { - Wound infection (1) }\end{array}$ \\
\hline $\begin{array}{l}\text { AV-fistula (for } \\
\text { dialysis) }\end{array}$ & $2(2.5)$ & - Repair & - None \\
\hline Total & $78(100)$ & & \\
\hline
\end{tabular}

DOI: http://dx.doi.org/10.4314/ejhs.v29i2.10 


\section{DISCUSSION}

The study is one of the articles that documented the pattern of vascular diseases in a tertiary referral hospital of Ethiopia (5-9). Even though TASH serves as a central referral hospital for vascular diseases, the management provided to the patients is still sub-optimal. During the study period, we could only operate on $78(20 \%$ of the patients waiting for intervention). This is because of the challenge we had: lack of systems for patient selection, prioritization and care; absence of dedicated ward and operating room for patients with vascular disease; frequent power outages and autoclave breakdowns; shortage of trained vascular surgeons and extremely high shortage of consumables like vascular grafts and sutures. So far, all the reported surgeries could be done using materials donated from other countries. Besides, though our hospital recently owns new Cath-lab, all patients who presented with PAD requiring either balloon angioplasty or stent were managed medically for lack of consumables.

In developing countries, over the last decade, numerous reports and anecdotal reviews attest to the increased incidence of vascular disease (3). In comparison to a report made during 2010/2011 at TASH, there is an increment in the prevalence and pattern of vascular disease (5). Factors that could contribute to these increased reports of vascular disease could be an increase in the incidence of non-communicable disease, and better diagnostic and treatment facilities.

Similar to other studies done in developed nations, men are affected more than women (10). The mean age of presentation was $39+/-10$ years, which shows that our patients are younger than those in developed country $(2,3,11)$. PAD accounts for the majority $(33.2 \%)$ of cases seen at vascular surgery clinic, and the majority of them have femoral artery disease. This figure is similar to data collected from developed nations where the prevalence of PAD is estimated to be $10 \%-$ $25 \%$ in people aged $>55$ years and increases to approximately $40 \%$ in community populations aged $>80$ years $(13,14)$.
In USA, about 4-8 million people are affected by PAD, and recent studies have reported an increase in PAD globally over the last decade $(11,14-16)$. Other commonly seen cases were chemodectomas and varicose vein. Some studies have shown that long exposure to high altitudes appears to be correlated with a 10-fold higher incidence of carotid body tumors. Our region is a high altitude plateau, and the higher incidence of Chemodectomas could be related to it $(20,21)$. The number of varicose vein surgery is limited because such kind of surgery gets less priority for admission and is usually referred back to the regional hospitals.

Aneurysmal diseases are also not a rare occurrence. The most common affected artery is Femoral artery $(33.3 \%)$ which is also the case in Western countries with predominantly Caucasian populations where femoro-popliteal aneurysms comprise $70-85 \%$ of peripheral aneurysms $(18,19)$. Globally, the second common cause of death from conditions requiring emergency surgery excluding obstetrics and trauma was aortic aneurysm with peripheral vascular disease being the sixth one (4), which is not the case in our setup. The reason behind could be lack of data, misdiagnosis, or lack of access to urgent surgical care resulting death out side of the hospital. Unlike most centers for vascular surgery $(19,20)$, we did only 2 artriovenous fistula. This happens because the dialysis center in our hospital serves only for patients with ARF, which does not require artriovenous fistula.

$\mathrm{PAD}$ and trauma remains the major indications for vascular intervention that account for $28(35.9 \%)$ and $22(28.2 \%)$, respectively. Brachial artery injuries due stab accounted for more than two-third of trauma victims. A similar pattern was also reported in other African countries (22-24). Because of its late presentation, post-traumatic vascular emergencies has presented a particularly challenge. The late presentation results in organ loss and sometimes even death. In our study, we used 7 RSVG (Reverse saphenous vein graft) for segmental arterial replacement. 
Thomas and colleagues (22) had a different experience because they used more prosthetic grafts than RSVG. Ajibade and colleagues (24) reported that of 132 patients who required amputation, trauma constituted the major indication $(42.4 \%)$. Similar findings have been reported in other studies in which trauma remains the major indication for amputation $(7,8.9,25,26)$.

In our institution, those patients with vascular injury who presented late with gangrene will end up with the orthopedic surgeons for amputation as reported by Ajibade (25) and colleagues. Hypertension and Diabetes mellitus were found the commonly associated diseases, especially for PAD and aortic aneurysms. Onefourth of the total vascular and two-third of PAD patient were smokers. This trend mirrors that of the risk factors for vascular diseases in developed nations; namely, tobacco use, diabetes mellitus and hypertension $(4,11)$.

Considering that we collected data from series of cases that visited our clinic, the study may not appropriately represent the wider population. Even though there is a high volume of vascular disease at TASH, our practice for vascular surgery is still not sufficient. To alleviate this problem, the Department of Surgery has developed a strategic plan that will help to train more vascular surgeons and improve the service. A curriculum for vascular surgery training is now developed and approved. In order to support the training, MOU was also signed with the University of Wisconsin (USA) and the University of Linköping (Sweden). Currently, two general surgeons and three residents have expressed their interest and started their training in vascular surgery. Such initiatives, however, need to be backed by a corresponding zeal from the management. We not only need support for the training but also a concerted effort from the management to procure the necessary materials and equipment. The Ministry of health should also encourage investments through public private partnership. This will eventually support the training, service and research of vascular problems.

\section{REFERENCES}

1. Alan D, Colin D, Majid E, et al. Global Burden of Disease and Risk Factors. 2006. Washington (DC): The International Bank for Reconstruction and Development / The World Bank; New York: Oxford University Press; 2006. ISBN-10: 0-8213-62623ISBN-13: 978-0-8213-6262-4.

2. World Health Organization; WHO, editor. Global disease burden, Global status report on noncommunicable disease 2010; Geneva, Switzerland: WHO; 2011;ISBN 9789241564229.

3. Stewart B, Khanduri P, McCord C, et al. Global disease burden of conditions requiring emergency surgery; 2014; BJS; 101(1) e9-22, doi: 10.1002/bjs.9329.Epub 2013 Nov25.

4. S. D. Hobbs, A. B. M. Wilmink, A. W. Bradbury. Ethnicity and Peripheral Arterial Disease. Eur J Vasc Endovasc Surg, 2003; 25(6):505-512;doi.org/10.1053 /ejvs.2001 1884.

5. E. Teffera, S. Kassa, A Ali. Patterns of Cardiothoracic and vascular surgical admissions at a tertiary University hospital AddisAbaba, Ethiopia. East central and southern Africa journal of surgery, 2013; 18:121-127.

6. Berhe Gebreslassie, Kibrom Gebreselassie, Reiye Esayas. Patterns and Causes of Amputation in Ayder Referral Hospital, Mekelle, Ethiopia: A Three-Year Experience, Ethiop J Health Sci.; 2018, 28(1): 31-36.

7. Manyazewal Dessie. Preventable amputation in Ethiopia. East and Central African Journal of Surgery; 2004; 9(1): -16-19.

8. Haileab Fekadu Wolde, Asrat Atsedeweyen, Addisu Jember. Predictors of vascular complications among type 2 diabetes mellitus patients at University of Gondar Referral Hospital: a retrospective follow-up study. BMC Endocrine Disorders 2018;18:52.

9. Mohammed Kedir, Abebe Bekele, Surgery of traumatic peripheral arterial injury with delayed transfer during the Ethio-Eritrean 
War - 1997-2000; East and Central African Journal of Surgery, 2004; 9 (1):20-23.

10.Ageliki G. Vouyouka, and K. Craig Kent. Arterial vascular disease in women. $J$ Vasc Surg 2007;46:1295-302.

11.Selvin E, Erlinger TP. Prevalence of and risk factors for peripheral arterial disease in the united states: Results from the national health and nutrition examination survey, 1999-2000; Circulation, 2004; 110(6): 738.

12.Norman PE, Eikelboom, JW, Hankey GJ. Peripheral arterial disease: Prognostic significance and prevention of atherothrombotic complications. Med. J. Aust. 2004; 181(3):150-154.

13. Stein B, Bert V, Jan D. To screen or not to screen for peripheral arterial disease in subjects aged 80 and over in primary health care: A cross-sectional analysis from the BELFRAIL study. BMC Family Pract. 2011; 12:39.

14. Hirsch AT, Criqui MH, Treat-Jacobson D, et al ;Peripheral arterial disease detection, awareness, and treatment in primary care. JAMA, 2001; 286(11): 1317-24.

15.Allison MA, Ho E, Denenberg, JO, et al. Ethnic-specific prevalence of peripheral arterial disease in the United States. $A m J$ Prev Med2007; 32(4): 328-333.

16. Fowkes FG, Rudan D, Rudan I, et al. Comparison of global estimates of prevalence and risk factors for peripheral artery disease in 2000 and 2010: A systematic review and analysis. Lancet 2013, 382, 1329-1340.

17.Conte MS,Pomposelli FB, Clair DG, et al. Society for vascular surgery practice guidelines for atherosclerotic occlusive disease of the lower extremities: Management of asymptomatic disease and claudication. J. Vasc. Surg. 2015, 61: S2S41.
18.Diwan A, Sarkar R, Stanley JC, Zelenock GB, Wakefield TW. Incidence of femoral and popliteal artery aneurysms in patients with abdominal aortic aneurysms. $J$ Vasc Surg. 2000; 31(5): 863-9.

19.Funk LM, Weiser TG, Berry WR, Lipsitz $\mathrm{SR}$, Merry $\mathrm{AF}$, et al. Global operating theatre distribution and pulse oximetry supply: an estimation from reported data. Lancet 2010; 376: 1055-1061.

20.Echejoh GO, Silas OA, Manasseh AN, Mandong BM, Adoga AS. Chemodectoma: three case-series with review of literature, Journal of Medicine and Medical Science. 2011;2(5): 849-853.

21. Thomas MO, Giwa SO, Adekoya-Cole TO. Arterial injuries in civilian practice in Lagos Nigeria. Niger J Clin Pract 2005; 8(2): 65-68. PMID: 16477855

22. Adebonojo SA. The status of cardiovascular surgery in West Africa [Review]. J Natl Med Assoc 1987; 79: 1077-1087, PMID : 3316674

23. Adeoye PO, Adebola SO, Adesiyun OA and Braimoh KT. Peripheral vascular surgical procedures in Ilorin, Nigeria: indications and outcome. Afr Health Sci 2011; 11: 433437, PMID: 22275935.

24.Ajibade A, Akinniyi OT, Okoye CS. Indications and complications of major limb amputations in Kano, Nigeria. Ghana Med $J$ 2013; 47(4): 185-188.

25.Kidmas AT, Nwadiaro CH, Igun GO. Lower limb amputation in Jos. Nigeria;East Afr Med J 2004; 81: 427-429.

26. Onuminya JE, Obekpa PO, Ihezue HC, Ukegbu ND and Onabowale BO. Major amputations in Nigeria: a plea to educate traditional bonesetters. Trop Doct 2000; 30: 133-213. 